\title{
FLOW-INJECTION SPECTROPHOTOMETRIC DETERMINATION OF TETRACYCLINE AND DOXYCYCLINE IN PHARMACEUTICAL FORMULATIONS USING CHLORAMINE-T AS OXIDIZING AGENT
}

\author{
José L. Rufino, Patrícia L. Weinert, Helena R. Pezza e Leonardo Pezza* \\ Instituto de Química de Araraquara, Universidade Estadual Paulista, CP 355, 14801-970 Araraquara - SP, Brasil
}

Recebido em 6/8/08; aceito em 5/3/09; publicado na web em 4/8/09

\begin{abstract}
FLOW-INJECTION SPECTROPHOTOMETRIC DETERMINATION OF TETRACYCLINE AND DOXYCYCLINE IN PHARMACEUTICAL FORMULATIONS USING CHLORAMINE-T AS OXIDIZING AGENT. A flow-injection (FI) spectrophotometric procedure is proposed for tetracycline (TC) and doxycycline (DXC) determination in pharmaceuticals. The method is based on the reaction of oxidation of these drugs by chloramine-T in alkaline medium producing red color products $\left(\lambda_{\max }=535\right.$ and $525 \mathrm{~nm}$ ). Beer's law is obeyed in the concentration range from $6.62 \times 10^{-5}$ to $7.72 \times 10^{-4} \mathrm{~mol} \mathrm{~L}^{-1}$ and $5.37 \times 10^{-5}$ to $7.16 \times 10^{-4} \mathrm{~mol} \mathrm{~L}^{-1}$ for TC and DXC, respectively. The analytical frequency was $50 \mathrm{~h}^{-1}$ and $45 \mathrm{~h}^{-1}$ for TC and DXC, respectively. The results obtained by the proposed method were in good agreement with those obtained by the official method at $95 \%$ confidence level.
\end{abstract}

Keywords: tetracyclines; flow-injection; spectrophotometry.

\section{INTRODUCTION}

Tetracyclines (TCs) represent a class of antibacterial compounds with broad spectrum antibiotics for their high activity against nearly all gram-positive and gram-negative bacteria. Due to their broad antibacterial spectrum and economic advantages, TCs have been commonly used in human pathologies as well as in veterinary medicine, animal nutrition and feed additives for cattle growth. It is used for many different infections, such as respiratory tract infections, urethritis and severe acne. It also has a role in the treatment of multidrug resistant malaria. ${ }^{1-4}$

Owing to their extensive use in infectious diseases therapy, there have been several analytical methods reported for their determination, both in pharmaceutical formulations and biological samples (fluids and tissues) including spectrophotometry, ${ }^{5-8}$ capillary electrophoresis, ${ }^{9}$ chemiluminescence, ${ }^{10}$ fluorimetry, ${ }^{11-13} \mathrm{NIR},{ }^{14}$ and HPLC. ${ }^{15-21}$ Most of these methods require elaborate instrumentation or have a low sampling frequency.

The official monographs of the United States Pharmacopoeia ${ }^{22}$ describe methods for the determination of tetracycline (TC) and doxycycline (DXC) in pharmaceutical formulations using highperformance liquid chromatography (HPLC), but each compound requires different conditions for determination. The biological assay proposed by the British Pharmacopoeia ${ }^{23}$ is time-consuming and not suitable for routine analysis.

Since the conventional spectrophotometric methods for tetracyclines determinations are tedious and time consuming, flow injection analysis (FIA) methods with chemiluminescence, ${ }^{24-27}$ amperometric ${ }^{28-30}$ and spectrophotometric ${ }^{31-34}$ detection have been employed instead.

The automated flow injection analysis systems with spectrophotometric detection present as main disadvantages the relatively high cost of reagents, ${ }^{32}$ very low sampling rate ${ }^{34}$ and low selectivity. ${ }^{31,33}$ The methodologies that employ flow systems with amperometric ${ }^{28-30}$ and chemiluminescence detection, ${ }^{24-27}$ despite their high analytical sensitivity, present the disadvantages of relative high $\cos ^{28-30}$ as well as the use of oxidizing reagents which are expensive ${ }^{25}$ or highly toxic..$^{26,27}$

Visible absorption spectrophotometry was applied in pioneering works on flow injection analysis. ${ }^{35,36}$ Through all the thirty-three years of development of FIA, UV-vis spectrophotometry has been and currently is the most common detection used in FIA. ${ }^{37} \mathrm{UV}-\mathrm{Vis}$

*e-mail: pezza@iq.unesp.br spectrophotometry is the technique of choice for FIA pharmaceutical applications, as it offers the advantages of simple and low cost instruments that are available at all laboratories. ${ }^{37,38}$

The main purpose of this work was to develop a simple, fast and low-cost flow injection procedure for the quantification of tetracycline and doxycycline based on the spectrophotometric detection of the colored products formed by the oxidation of these drugs with chloramine- $\mathrm{T}$ (CAT) in alkaline medium. The resulting colored products of the abovementioned reaction of tetracycline or doxycycline with CAT are measured at 535 and $525 \mathrm{~nm}$, respectively.

\section{EXPERIMENTAL}

\section{Apparatus}

A Gilson Minipuls 3 peristaltic pump (Gilson, Villiers-le-Bel, France) multichannel peristaltic pump was employed for fluid propelling. Samples and working standard solutions were inserted in the flow system with the aid of three-piece manual injector-commutator. A spectrophotometer USB 4000 (Ocean Optics, Dunedin, USA) equipped with a flow-cell of $10 \mathrm{~mm}$ path length and $80 \mu \mathrm{L}$ inner volume was used for the continuously monitoring of the absorbance.

The samples were pumped through Tygon ${ }^{\circledR}$ pumping tube of 1.85 mm i.d., sodium carbonate solution was pumped through Tygon ${ }^{\circledR}$ pumping tube of $1.02 \mathrm{~mm}$ i.d. and CAT solution pumped through Tygon ${ }^{\circledR}$ pumping tube of $2.06 \mathrm{~mm}$ i.d. The sample loop and reaction coils were made of polytetrafluoroethylene tubes (PTFE) of 0.8 mm i.d.; and the confluences in acrylic. End-fittings and connectors (Omnifit, New York, USA) were used.

A thermostatic bath equipped with a PT-100 temperature sensor having a resolution of $0.1{ }^{\circ} \mathrm{C}$ and a N322-T digital temperature controller was used for heating.

\section{Reagents and analytical solutions}

High purity deionized water (resistivity $18.2 \mathrm{M} \Omega \mathrm{cm}$ ) obtained by using a Milli-Q Plus system (Millipore Corp., Bedford, MA, USA) was used throughout. All reagents were of analytical grade. The excipients used in the interference study were of pharmaceutical grade.

Stock solution of sodium carbonate (E. Merck, Darmstadt, Ger- 
many) $1.0 \%(\mathrm{w} / \mathrm{v})$ was prepared in water and working solutions were prepared by appropriate dilution of the stock solution.

Solutions of chloramine-T trihydrate (J.T.Baker, Mexico, purity Active Chlorine 13\%) 4.0 and $4.5 \%(\mathrm{~m} / \mathrm{v})$ were prepared in water; the solution was stable for a period of 2 weeks when refrigerated at $4{ }^{\circ} \mathrm{C}$.

Pharmaceutical grade tetracycline hydrochloride was purchased from Henrifarma (Brazil, purity 99.3\%) and standard solution was daily prepared as $1.10 \times 10^{-3} \mathrm{~mol} \mathrm{~L}^{-1}$ in water; doxycycline hydrochloride was purchased from Deg (Brazil, purity 99.0\%) and standard solution was daily prepared as $8.95 \times 10^{-4} \mathrm{~mol} \mathrm{~L}^{-1}$ in water. Working standard solutions $\left(6.62 \times 10^{-5}\right.$ to $6.62 \times 10^{-4}$ mol L-1 of TC and $5.37 \times 10^{-5}$ to $6.27 \times 10^{-4} \mathrm{~mol} \mathrm{~L}^{-1}$ of DXC) were prepared separately by appropriate dilution of the standard solutions in water.

\section{Optimization of variables}

The optimization of all variables was performed by using a multivariate methodology. The variables were studied first using fractional factorial design and subsequently the two most significant variables were studied using the response surface methodology. ${ }^{39}$ All statistical calculations were performed using Statistic 6.0 software.

\section{Recommended procedure}

The FIA system is depicted in (Figure 1). At the position specified in the figure, a sample volume is selected by the loop (L). After loop-based injection, the TC or DX solution is loaded via the porter $\left(\mathrm{H}_{2} \mathrm{O}\right)$ and merged at the confluent point with $\mathrm{Na}_{2} \mathrm{CO}_{3}$ solution and alkalinized inside the reactor coil (R1), subsequently oxidized by chloramine-T inside the reactor coil (R2), which was heated in a water bath, forming red color products and finally passed through reactor coil (R3), which was cooled in an ice bath. Passage of the colored compound through the flow injection spectrophotometric cell at room temperature, results in a transient signal that is recorded as absorbance ( $535 \mathrm{~nm}$ for TC or $525 \mathrm{~nm}$ for DXC) which is proportional to the tetracycline or doxycycline content in the sample. After absorbance maximum measurement, the manual injector-commutator is switched back to the initial position starting another cycle.

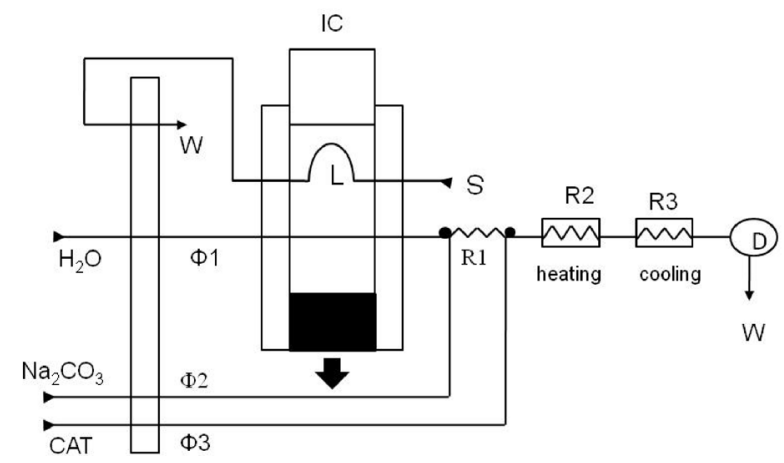

Figure 1. Flow diagram of the FIA system used. IC: injector-commutator; L: sampling loop; S: sample or analytical solutions; $\Phi 1$ : flow at $1.4 \mathrm{~mL} \mathrm{~min}^{-1}$ (sample loader); $\Phi 2$ : flow at $0.6 \mathrm{~mL} \mathrm{~min}^{-1}$; $\Phi 3$ : flow at $1.7 \mathrm{~mL} \mathrm{~min}^{-1}$; R1 and R2: coiled reactor (0.8 mm i.d.); $R 3$ : cooling coil (0.8 mm i.d.); •: confluent points; PP: peristaltic pump; D: detector; W: wastes. Black area: next position of the injector-commutator. Black arrow pointing downwards indicates the movement of the central part of the IC

\section{Samples preparation}

Two commercial samples of pharmaceutical formulations (capsules) containing $500 \mathrm{mg}$ of tetracycline hydrochloride and three containing $100 \mathrm{mg}$ of doxycycline hydrochloride from different batches and different brands were purchased in local drugstores in Araraquara city, (Brazil) and analysed by the proposed method.

Ten tablets (or capsules) of each commercial brand pharmaceutical to be studied were weighed exactly; the tablets were grounded to a fine powder and homogenized. A portion of this powder equivalent to approximately $25 \mathrm{mg}$ of drug was accurately weighed. The sample was dissolved with $25 \mathrm{~mL}$ of water, transferred to a $50 \mathrm{~mL}$ volumetric flask and the volume was completed with water. In the sequence, this solution was filtered through Whatman 41 filter-paper. The first few milliliters of the filtrate were discarded and an aliquot of $4.0 \mathrm{~mL}$ of the filtrate was transferred to a $10 \mathrm{~mL}$ volumetric flask and the volume was completed with water. All samples were analyzed according to the recommended procedure.

\section{RESULTS AND DISCUSSION}

\section{Preliminary tests}

Chloramine-T (CAT; sodium $N$-chloro- $p$-toluenesulfonamide) is a valuable reagent for the determination of many organic compounds of therapeutic interest. Its use depends mainly on its ability to cause oxidation of diverse functional groups in both acidic and alkaline media. ${ }^{40-43}$

In the literature is described a method in batch for determination of tetracycline with chloramine-T and gallocyanine. The method is indirect and involves the addition of excess CAT of a known concentration in the presence of $\mathrm{HCl}$ and the determination of the unreacted CAT by measurement of the decrease in the absorbance of the dye gallocyanine. ${ }^{44}$

Preliminary experimental results revealed that the reaction of $\mathrm{TC}$ and DXC with CAT in an alkaline medium of $\mathrm{Na}_{2} \mathrm{CO}_{3}$ produces a red color product at room temperature. Full color development took $15 \mathrm{~min}$ for TC and $60 \mathrm{~min}$ for DXC. However, the speed of the reaction can be increased with heating and the color developed more rapidly. The Figure 1S (Supplementary Material), shows the spectra of the reactions of tetracycline and doxycycline with CAT in a medium of $\mathrm{Na}_{2} \mathrm{CO}_{3}$ after heating for five minutes to the $65^{\circ} \mathrm{C}$ obtained in batch.

\section{Optimization of variables}

Due to the fact that more than one variable is potentially important, and that it would be difficult to optimize the conditions through a uni-variant optimization procedure, the experimental conditions were obtained using a chemiometric experimental design. Factorial designs are widely used in experiments involving several factors where it is necessary to investigate the effects of the factors on a response variable.

The fractional factorial designs are among widely used types of designs in the screening experiments. These are experiments in which many factors are considered with the purpose of identifying these factors that have large effects. The screening experiments are usually performed early in a response surface study when it is likely that many of the factors initially considered have little or no effect on the response. ${ }^{39}$

Initially the influence of the variables (loop-size of sample, flow rate, temperature, the reactor size of $\mathrm{R} 1$ and $\mathrm{R} 2$, CAT and $\mathrm{Na}_{2} \mathrm{CO}_{3}$ concentration) were examined by $2^{(7-3)}$ fractional factorial design. The 
size of coil R3 was fixed at $50 \mathrm{~cm}$ having as its objective only the cooling of the product suppressing the micro blisters formed during the heating. In this design, each variable was studied in two levels: low (-1) and high (+1). For this design, 16 experiments were necessary, which were realized in triplicate and randomized to eliminate environmental variation. The variables and their levels are summarized in Table 1. The highest and lowest values of each variable were defined based on preliminary experiments. The flow rate was studied by varying the rotation speed of the peristaltic pump.

Table 1. Nominal values of each variable corresponding to levels studied

\begin{tabular}{lcccc}
\hline \multirow{2}{*}{ Variables } & \multicolumn{2}{c}{ Tetracycline } & \multicolumn{2}{c}{ Doxycycline } \\
& Low level & High level & Low level & High level \\
\hline $\begin{array}{l}\mathrm{Na}_{2} \mathrm{CO}_{3} \% \\
(\mathrm{~m} / \mathrm{v})\end{array}$ & 0.20 & 0.30 & 0.15 & 0.20 \\
$\begin{array}{l}\mathrm{CAT} \%(\mathrm{~m} / \mathrm{v}) \\
\begin{array}{l}\text { Loop-size } \\
(\mathrm{cm})\end{array}\end{array}$ & 3.00 & 4.00 & 4.00 & 4.50 \\
$\begin{array}{l}\text { Reactor } 1 \\
(\mathrm{~cm})\end{array}$ & 50 & 80 & 80 & 110 \\
$\begin{array}{l}\text { Reactor } 2 \\
(\mathrm{~cm})\end{array}$ & 10 & 15 & 10 & 15 \\
$\begin{array}{l}\text { Temperature } \\
\left({ }^{\circ} \mathrm{C}\right)\end{array}$ & 65 & 70 & 65 & 70 \\
$\begin{array}{l}\text { Peristaltic } \\
\text { pump (rpm) }\end{array}$ & 7.5 & 10 & 7.5 & 10 \\
\hline
\end{tabular}

The results are represented in the Pareto chart (Figures 2 and 3), which is a horizontal bar-chart. The length of each bar on the chart and their signs are proportional to the absolute value of its associated estimated effect or the standardized effect. Signs positive indicate that the absorbance is increased with increase of the value of the respective variable within the range studied, while signs negative indicate what the absorbance is favored with decreased of the variable. The chart includes a vertical line that corresponds to the $95 \%$ limit indicating statistical significance. An effect is therefore significant if its corresponding bar crosses this vertical line.

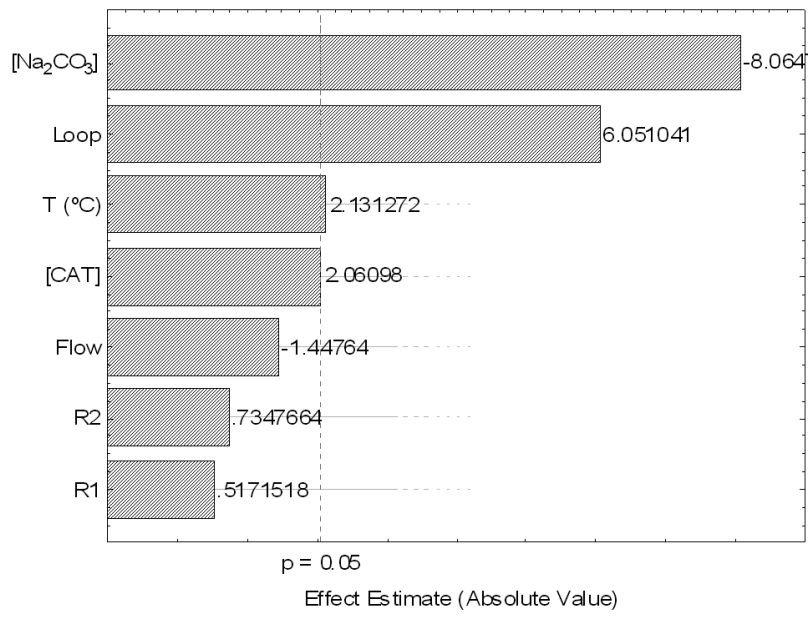

Figure 2. Pareto chart for visualizing the effects of the FI and chemical variables on the absorbance measurements using $2^{(7-3)}$ factorial design for optimization of tetracycline
The Figure 2, shows the Pareto-chart for the TC, where the variables temperature, reactor-size of R1, R2 and CAT concentration are considered not to be significant and these variables were adjusted to a high level $(+1)$; the flow rate not significant with negative sign adjusted to a low level (-1). The variables loop-size and $\mathrm{Na}_{2} \mathrm{CO}_{3}$ concentration were significant at the $95 \%$ confidence level. Hence, these effects were studied more carefully by response surface methodology in five levels including four central points for statistical validity within the range -1.41 to +1.41 , which corresponds to the loop with a size range of 85 to $115 \mathrm{~cm}$ and $\mathrm{Na}_{2} \mathrm{CO}_{3}$ with a concentration range 0.12 to $0.25 \%(\mathrm{~m} / \mathrm{v})$

However, the Figure 3, shows that for DXC, only the reactor R1 is considered not to be significant and fixed in the level $(-1)$. The loop-size has a small effect positive and was considered not to be significant, being adjusted in the level more high. The flow rate has an effect negative, but for obtains reasonable analytical frequency, the flow rate was chosen in the low level $(-1)$.

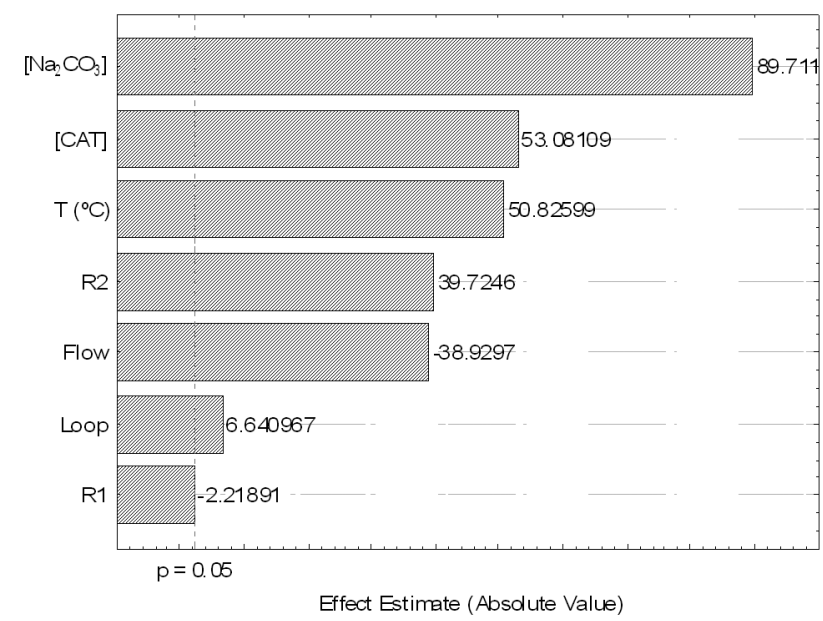

Figure 3. Pareto chart for visualizing the effects of the FI and chemical variables on the absorbance measurements using $2^{(7-3)}$ factorial design for optimization of doxycycline

In the sequence, the variables (temperature, the reactor size of R2, CAT and $\mathrm{Na}_{2} \mathrm{CO}_{3}$ concentration) were optimized using now experimental design $2^{4-1}$ factorial. The Figure 4 , shows the effect of each variable correspondent to the response at $95 \%$ confidence level. It can be observed in this figure that the temperature and $\mathrm{Na}_{2} \mathrm{CO}_{3}$ concentration are the variables most significant. The individual effects of the reactor-size R2 and CAT concentration also were significant, but less important; due the positive sign were fixed in the level more high.

Afterwards, the variables most significant (temperature and $\mathrm{Na}_{2} \mathrm{CO}_{3}$ concentration) were optimized by response surface methodology. These variables were studied in five levels including four central points for statistical validity within range -1.41 to +1.41 , which corresponds to the temperature with range of 75 to $80{ }^{\circ} \mathrm{C}$ and $\mathrm{Na}_{2} \mathrm{CO}_{3}$ with a concentration range 0.12 to $0.25 \%(\mathrm{~m} / \mathrm{v})$.

The Figures $2 \mathrm{~S}$ and $3 \mathrm{~S}$, depict the surfaces response, showing the optimum conditions of the variables for TC and DXC, respectively. It is possible to identify that the points referring to the best conditions were: loop of $103 \mathrm{~cm}$ and $\mathrm{Na}_{2} \mathrm{CO}_{3}$ concentration equal to $0.18 \%(\mathrm{~m} / \mathrm{v})$ for TC (Figure $2 \mathrm{~S}$ ); temperature of $77.5^{\circ} \mathrm{C}$ and $\mathrm{Na}_{2} \mathrm{CO}_{3}$ concentration equal to $0.20 \%(\mathrm{~m} / \mathrm{v})$ for DXC (Figure $3 \mathrm{~S})$.

The responses of the models $\mathrm{R}^{2}$ values were greater than 0.95 , implying that the models were well fitted by the data for the absorbance response (peak height). In Table 2, the optimum values of all the variables studied are shown. 


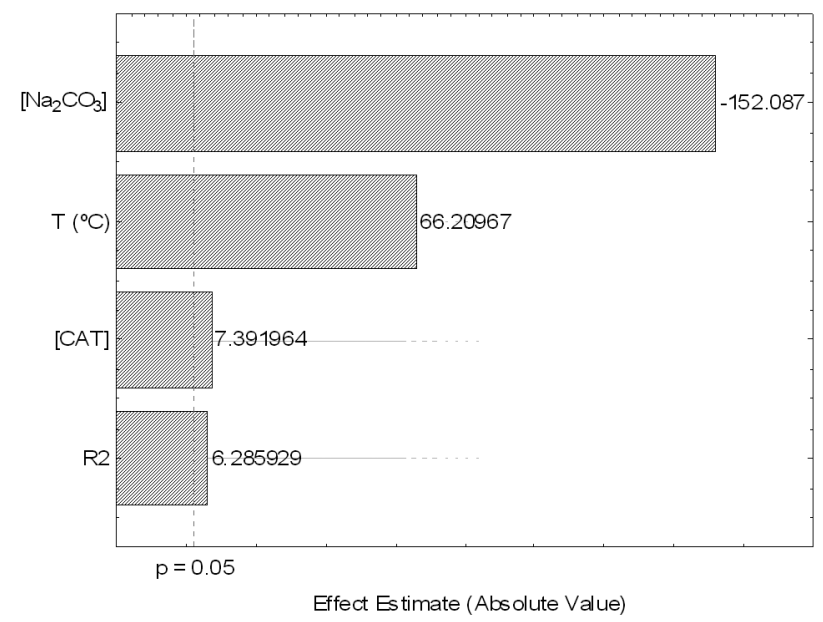

Figure 4. Pareto chart for visualizing the effects of the FI and chemical variables on the absorbance measurements using $2^{(4-1)}$ factorial design for optimization of doxycycline

Table 2. Optimization of chemical and flow injection parameter for the analysis of TC and DXC

\begin{tabular}{lcc}
\hline \multirow{2}{*}{ Parameters } & \multicolumn{2}{c}{ Optimum value } \\
& Tetracycline & Doxycycline \\
\hline $\mathrm{Na}_{2} \mathrm{CO}_{3} \%(\mathrm{~m} / \mathrm{v})$ & 0.18 & 0.20 \\
$\mathrm{CAT} \%(\mathrm{~m} / \mathrm{v})$ & 4.00 & 4.50 \\
Loop-size $(\mathrm{cm})$ & 103 & 110 \\
Reactor $1(\mathrm{~cm})$ & 10 & 10 \\
Reactor $2(\mathrm{~cm})$ & 250 & 280 \\
Temperature $\left({ }^{\circ} \mathrm{C}\right)$ & 70.0 & 77.5 \\
Peristaltic pump $(\mathrm{rpm})$ & 7.5 & 7.5 \\
\hline
\end{tabular}

\section{Analytical data}

The developed analytical method was validated by evaluating the following parameters: ${ }^{45,46}$ linear dynamic range, precision, accurate, ruggedness, limit of detection (LOD) and limit of quantification (LOQ), as well as by applying the standard addition technique.

Under optimized experimental conditions, the analytical curves were constructed in triplicate. Table 3 contains the figures of merit for the proposed method for the determinations of TC and DXC. The analytical curves obtained showed good linearity within the range of concentrations used. The linear data were adjusted by equation $\mathbf{A}=\mathbf{a}$ $+\mathbf{b}[\mathbf{C}]$, where, $\mathbf{A}$ is the absorbance, $\mathbf{a}$ is the intercept, $\mathbf{b}$ is the slope and $[\mathbf{C}]$ is the drugs concentration in $\mathrm{mol} \mathrm{L}^{-1}$. The typical transient signals, in triplicate, corresponding to a linear analytical curve for drugs and samples were showed in the Figures $4 \mathrm{~S}$ and $5 \mathrm{~S}$.

The limit of detection (LOD) and limit of quantification (LOQ) were calculated according to Skoog et.al. ${ }^{46}$ using the following expressions: $\mathrm{LOD}=3 \sigma / \mathrm{b}$ and $\mathrm{LOQ}=10 \sigma / \mathrm{b}$, where $\sigma$ is the standard deviation of twenty measures of the blank and $b$ is the slope of the analytical curves. The results are summarized in Table 3.

The precision and accuracy were evaluated by comparing the results obtained from the analysis of pharmaceutical formulations by the proposed method with those obtained using the official HPLC methods. ${ }^{22}$ The results are summarized in Table 4 .

The susceptibility of the developed analytical method to changes was tested to evaluate the ruggedness of the method. For this purpose, the two experimental designs were employed where the variables were tested.

The matrix interference can introduce systematic errors on the analytical determination. In order to investigate the presence of matrix effects on the proposed method, a recovery study was realized. In this study, $1.04 \times 10^{-4}, 2.08 \times 10^{-4}, 3.15 \times 10^{-4}, 4.20 \times 10^{-4}$ mol L-1 of tetracycline reference solutions were added separately to each sample of tetracycline, and $8.68 \times 10^{-5}, 1.74 \times 10^{-4}, 2.61 \mathrm{x}$ $10^{-4}, 3.47 \times 10^{-4} \mathrm{~mol} \mathrm{~L}^{-1}$ of doxycycline reference solutions were added separately to each sample of doxycycline. The recoveries obtained by the standard addition method ranged from 96.7 to $102.3 \%$ indicating the absence of significant matrix effects on the proposed FI procedure.

The effects of the common excipients present in commercial pharmaceutical formulations such as: microcrystalline cellulose, hydroxypropylmethylcellulose, lactose, titanium dioxide, starch, talc, sodium lauryl-sulphate, sodic croscarmelose and magnesium stearate were carefully evaluated. It was exhibited that the presence of the abovementioned excipients up to 1 or 10-times of the weight ratio to tetracycline or doxycycline showed no interference effects for determination of these drugs.

\section{Analytical applications}

The applicability of the proposed method for the determination of TC and DXC in commercial dosage forms was examined by analyzing marketed products. The results were statistically ${ }^{47}$ compared with those obtained by the official methods of the US Pharmacopeia ${ }^{22}$ and are summarized in Table 4. In all cases, the calculated $t$ and $F$ values are less than the theoretical ones at $95 \%$ confidence level, indicating that there is no significant difference between either methods concerning precision and accuracy in the determination of TC and DXC in pharmaceutical formulations. The flow system proposed provides a sampling frequency of 50 and 45 samples $\mathrm{h}^{-1}$ for TC and DXC, respectively.

Table 3. Analytical characteristics of the proposed method

\begin{tabular}{lcc}
\hline Parameters & Doxycycline & Tetracycline \\
\hline$\lambda(\mathrm{nm})$ & 525 & 535 \\
Linear dynamic range / mol L-1 & $5.37 \times 10^{-5}$ to $7.16 \times 10^{-4}$ & $6.62 \times 10^{-5}$ to $7.72 \times 10^{-4}$ \\
Limit of detection / mol L-1 & $4.21 \times 10^{-6}$ & $3.76 \times 10^{-6}$ \\
Limit of quantification / mol L-1 & $1.39 \times 10^{-5}$ & $1.24 \times 10^{-5}$ \\
Intercept & -0.0234 & 0.0032 \\
Slope & 1637.93 & 1554.94 \\
Regression coefficient $(\mathrm{R})$ & 0.9994 & 0.9999 \\
\hline
\end{tabular}


Table 4. Determination of tetracycline and doxycycline in commercial pharmaceutical formulations

\begin{tabular}{|c|c|c|c|c|c|}
\hline Sample & Label to content ${ }^{a}$ & $\begin{array}{c}\text { Proposed Method } \\
\text { Found }^{\mathrm{b}}\end{array}$ & $\begin{array}{l}\text { Official Method }{ }^{22} \\
\text { Found }^{\mathrm{b}}\end{array}$ & $t$ value $(2.78)^{\mathrm{c}}$ & $F$ value $(19.00)^{\mathrm{c}}$ \\
\hline \multicolumn{6}{|c|}{ Tetracycline } \\
\hline A & 500 & $505.2 \pm 1.4$ & $505.7 \pm 0.6$ & 0.54 & 5.44 \\
\hline B & 500 & $502.3 \pm 0.4$ & $501.1 \pm 0.7$ & 2.52 & 3.06 \\
\hline \multicolumn{6}{|c|}{ Doxycycline } \\
\hline A & 100 & $105.9 \pm 0.8$ & $104.7 \pm 0.5$ & 2.19 & 2.56 \\
\hline B & 100 & $105.2 \pm 0.7$ & $103.7 \pm 0.7$ & 2.55 & 1.00 \\
\hline $\mathrm{C}$ & 100 & $103.4 \pm 0.9$ & $102.2 \pm 0.4$ & 2.08 & 4.75 \\
\hline
\end{tabular}

${ }^{\mathrm{a}} \mathrm{mg}$ tablet ${ }^{-1}$ or $\mathrm{mg}$ capsule ${ }^{-1}$; baverage \pm standard deviation (S.D) of three independent analysis;

'theoretical values of $t$ and $F$ at $95 \%$ confidence level

Despite the high frequency analytical related to the FI spectrophotometric method reported by Sultan et al. ${ }^{48}$ the same presents disadvantages with respect to the preparation of the sample, which needs to heating until 20 min to $60^{\circ} \mathrm{C}$. The FI spectrophotometric method described by Karlicek and Solich ${ }^{32}$ is sensible, however, all antibiotics (tetracycline, doxycycline, rolitetracycline and oxytetracycline) are determinate in the same wavelength and it is not possible differentiate the sample. In the FI spectrophotometric method proposed by Al-Tamrah and Alwarthan ${ }^{49}$ the measures are made in the region near to the UV and are subject the interferences of others composed used in pharmaceutical formulations.

Compared with the abovementioned FI spectrophotometric methods for determination of tetracyclines, the proposed method present a good analytical frequency, the preparation of standard and sample are simple and shows sufficient sensitivity for the determination of tetracyclines in pharmaceutical formulations.

\section{CONCLUSION}

The proposed spectrophotometric flow injection procedure for tetracycline and doxycycline determination is simple, inexpensive, allows rapid determination at low costs, and shows adequate selectivity, low limit of detection and very good precision and accuracy. The recommended procedure has been successfully applied to the determination of the two drugs in commercial pharmaceutical formulations. This method is thus suitable for routine analysis.

\section{SUPPLEMENTARY MATERIAL}

The Figures identified like $\mathrm{S}$ to the long of the text are available freely in http://quimicanova.sbq.org.br, in the form of file PDF.

\section{ACKNOWLEDGEMENTS}

The authors would like to thank FAPESP, CNPq and CAPES Foundations (Brazil) for the financial support.

\section{REFERENCES}

1. Masawat, P.; Slater, J. M.; Sens. Actuators B 2007, 124, 127.

2. Wen, Y.; Wang, Y.; Feng, Y.; Talanta 2006, 70, 153.

3. Spisso, B. F.; Jesus, A. L. O.; Araújo Junior, M. A. G.; Monteiro, M. A.; Anal. Chim. Acta 2007, 581, 108.

4. Treetepvijit, S.; Preechaworapun, A.; Praphairaksit, N.; Chuanuwatanakul, S.; Einaga, Y.; Chailapakul, O.; Talanta 2006, 68, 1329.

5. Emara, K. M.; Askal, H. F.; Saleh, G. A.; Talanta 1991, 38, 1219.
6. Khalec, M. M. A.; Mahrous, M. S.; Talanta 1983, 30, 792.

7. Sultan, S. M.; Analyst 1986, 111, 97.

8. Mahrous M. S.; Khalec, M. M. A.; Talanta 1984, 31, 289.

9. Mamani, M. V.; Farfán, J. A.; Reyes, F. G. R. Rath, S.; Talanta 2006, 70, 236.

10. Han, H.; He, Z.; Zeng, Y.; Anal. Sci. 1999, 15, 467.

11. Shtykov, S. N.; Smirnova, T. D.; Bylinkin, Y. G.; Zhemerichkin, D. A.; J. Anal. Chem. 2005, 60, 24.

12. Salinas, F.; De La Pena, A. M.; Meras, I. D.; Anal. Lett. 1990, $23,863$.

13. Chang, W. B.; Zhao, Y. B.; Li, Y. X.; Hu, L. Y.; Analyst 1992, 117, 1377.

14. Szlyk, E.; Kowalczyk-Marzec, A.; Koter, I.; Chem. Anal. 2007, 52, 605. (CA 146:487994)

15. Kazemifard, A. G.; Moore, D. E.; J. Pharm. Biomed. Anal. 1997, 16 , 689.

16. Pena, A.; Carmona, A.; Barbosa, A.; Lino, C.; Silveira, I.; Castillo, B.; J. Pharm. Biomed Anal. 1998, 18, 839.

17. Iwaki, K.; Okumura, N.; Yamazaki, M.; J. Chromatogr., A 1992, 623, 153.

18. Tsuji, K.; Robertson, J. H.; J. Pharm. Sci. 1976, 65, 400.

19. Oka, H.; Uno, K.; Harada, K. I.; Masaka, K.; Suzuki, M.; J. Chromatogr., A 1984, 298, 435 .

20. Hasan, T.; Cooperman, B. S.; J. Chromatogr., A 1985, 321, 462.

21. Ragazzi, E.; Veronese, G.; J. Chromatogr., A 1977, 134, 223.

22. United States Pharmacopeia, $26^{\text {th }}$ ed., Rockvillle, 2003.

23. Britsh Pharmacopoeia, HM Stationery Office: London, 1988.

24. Zheng, X.; Mei, Y.; Zhang, Z.; Anal. Chim. Acta 2001, 440, 143.

25. Townshend, A.; Ruengsitagoon, W.; Thongpoon, C.; Liawruangrath, S.; Anal. Chim. Acta 2005, 541, 105.

26. Zhang, X. R.; Baeyens,W. R. G.; VanDen Borre, A.; VanDer Weken, G.; Calokerinos, A. C.; Schulman, S. G.; Analyst 1995, 120, 463.

27. Havatzis, S. A.; Timotheau-Potamia, M. M.; Calokerinos, A. C.; Analyst 1993, 118,633 .

28. Wangfuengkanagul, N.; Siangproh, W.; Chailapakul, O.; Talanta 2004, 64, 1183.

29. Palaharn, S.; Charoenraks, T.; Wangfuengkanagul, N.; Grudpan, K.; Chailapakul, O.; Anal. Chim. Acta 2003, 499, 191.

30. Huamin, J.; Erkang, W.; Analyst 1988, 113, 1541.

31. Liawruangrath, S.; Liawruangrath, B.; Watanesk, S.; Ruengsitagoon, W.; Anal. Sci. 2006, 22, 15 .

32. Karlicek, R.; Solich, P.; Anal. Chim. Acta 1994, 285, 9.

33. Medina, A. R.; Marín, M. G. G.; Cordova, M. L. F.; Díaz, A. M.; Microchem. J. 2000, 65, 325.

34. Alwarthan, A. A.; Al-Tamrah, S. A.; Sultan, S. M.; Analyst 1991, 116, 183.

35. Ruzika, J.; Hansen, H.; Anal. Chim. Acta 1975, 78, 145. 
36. Stewart, K. K.; Beecher, G. R.; Hare, P. E.; Anal.Biochem. 1976, 70, 167.

37. Trojanowicz, M.; Flow injection analysis:Instrumental and application, World Scientific: New York, 2000.

38. Tzanavaras, P. D.; Themelis, D. G.; Anal. Chim. Acta 2007, 588, 1.

39. Montgomery, D. C.; Design and Analysis of Experiment, $2^{\text {nd }}$ ed., Willey: New York, 1984.

40. Basavaiah, K.; Prameela, H. C.; Il Farmaco 2003, 58, 527.

41. Trieff, N. M.; Ramanujam, V. M. S.; Forti, G. C.; Talanta 1977, 24 , 188

42. Issa, A. S.; Beltagy, Y. A.; Mahrous, M. S.; Talanta 1978, 25, 710.

43. Shivananda, K. N.; Jagadeesh, R. V.; Puttaswamy; Mahendra, K. N.; J. Molecular Catalysis A: Chemical 2006, 255, 159.
44. Sastry, C. S. P.; Srinivas, K. R.; Prasad, K. M. M. K.; Talanta 1996, 43, 1625.

45. International Conference on Harmonization ICH-Q2A, Guideline for Industry: Text on Validation of Analytical procedures, 1995.

46. Skoog, D. A.; Holler, F. J.; Nieman, T. A.; Principles of Instrumental Analysis, $5^{\text {th }}$ ed., Harcourt Brace Company: Philadelphia, 1998.

47. Miller, J. C.; Miller, J. N.; Statistics for Analytical Chemistry, $2^{\text {nd }}$ ed., Ellis Horwood Limited: London, 1992.

48. Sultan, S. M.; Suliman, F. E. O.; Duffuaa, S. O.; Abu-Abdoun, I. I.; Analyst 1992, 117, 1179.

49. Al-Tamrah, S. A.; Alwarthan, A. A.; Anal. Lett. 1992, 25, 1865. 
FLOW-INJECTION SPECTROPHOTOMETRIC DETERMINATION OF TETRACYCLINE AND DOXYCYCLINE IN PHARMACEUTICAL FORMULATIONS USING CHLORAMINE-T AS OXIDIZING AGENT

José L. Rufino, Patrícia L. Weinert, Helena R. Pezza e Leonardo Pezza*

Instituto de Química de Araraquara, Universidade Estadual Paulista, CP 355, 14801-970 Araraquara - SP, Brasil

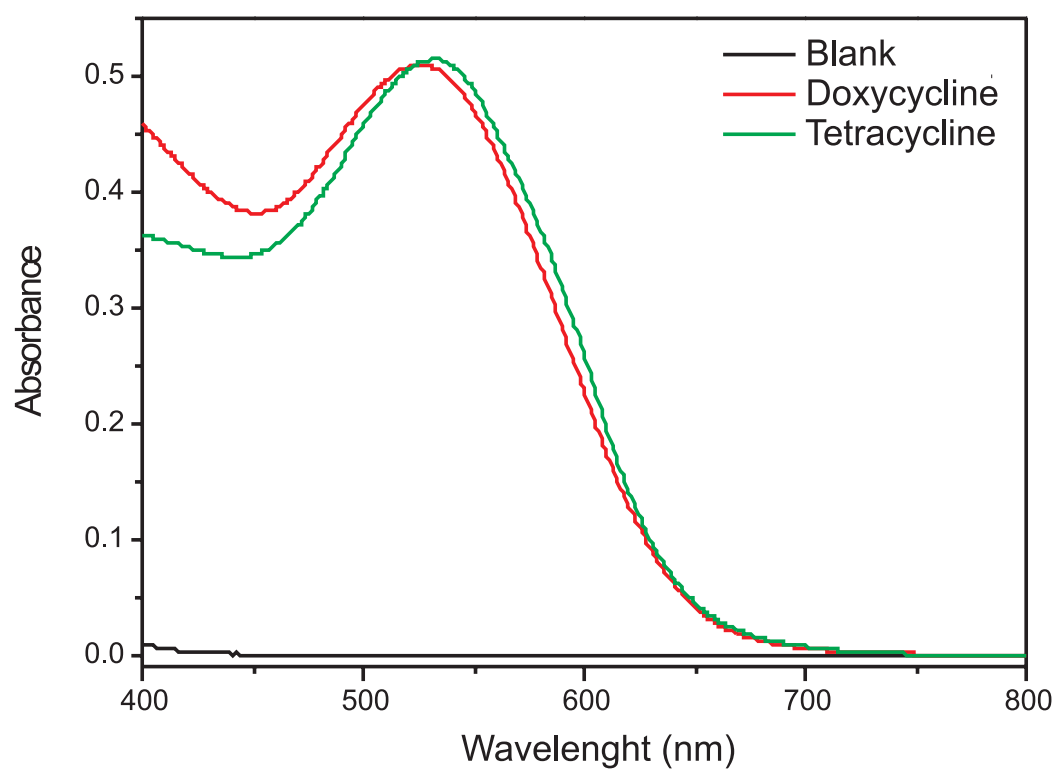

Figure 1S. Absorption spectrum of the reaction product obtained from tetracycline and doxycycline with Chloramine-Tin $\mathrm{Na}_{2} \mathrm{CO}_{3}$ medium. Absorbance values

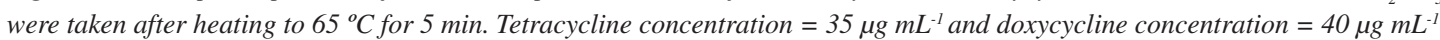

*e-mail: pezza@iq.unesp.br 


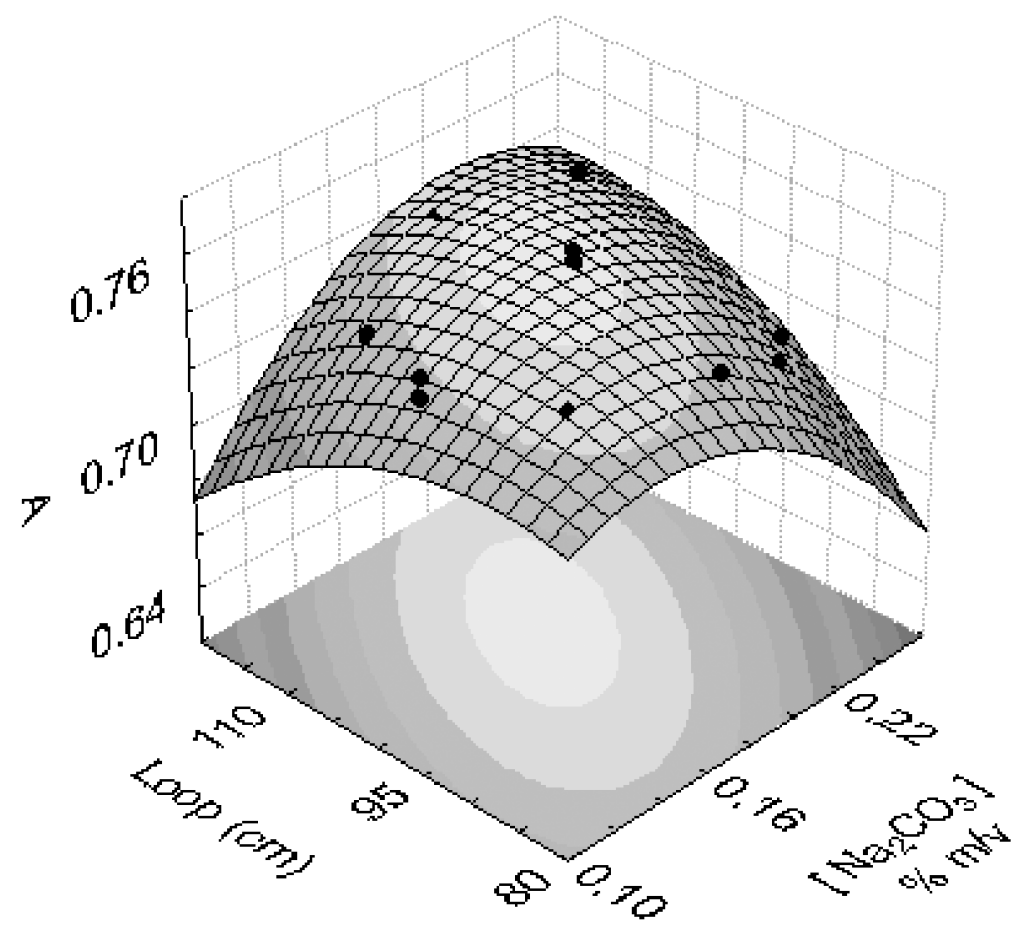

Figure 2S. Three-dimensional plot of the optimized response surface showing the absorbance as a function of $\mathrm{Na}_{2} \mathrm{CO}_{3}$ concentration and of loop-size

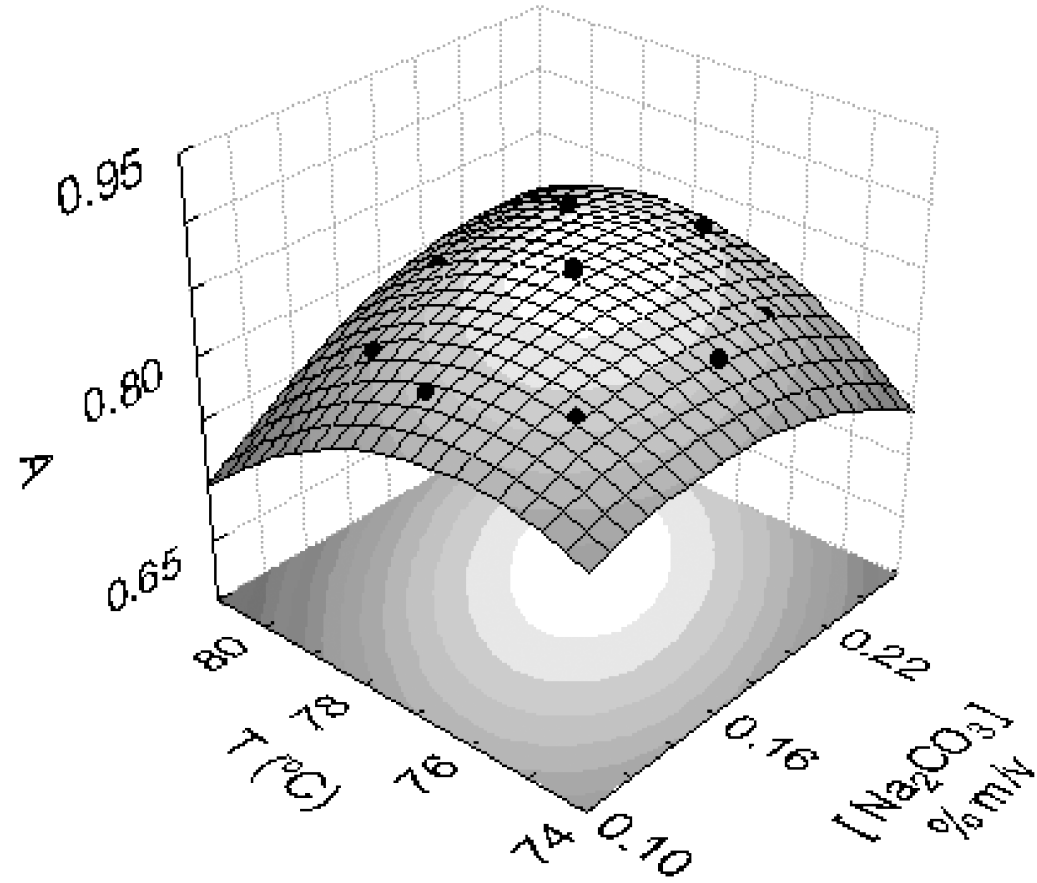

Figure 3S. Three-dimensional plot of the optimized response surface showing the absorbance as a function of $\mathrm{Na}_{2} \mathrm{CO}_{3}$ concentration and of the temperature 


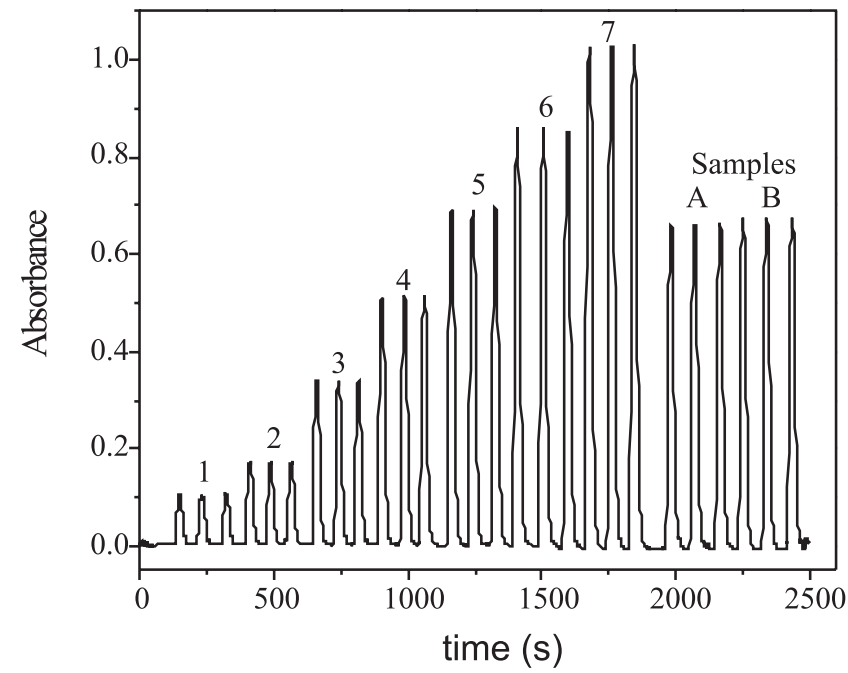

Figure 4S. Transient signals related to TC determination. From the left $(A)$, recorded peaks refer to a seven analytical solutions $\left(6.62 \times 10^{-5}, 1.10 \times 10^{-4}, 2.20 \times 10^{-4}\right.$, $3.31 \times 10^{-4}, 4.41 \times 10^{-4}, 5.51 \times 10^{-4}$, and $\left.6.62 \times 10^{-4}\right) \mathrm{mol} \mathrm{L}^{-1}$ plus two samples (A and B) processed three times

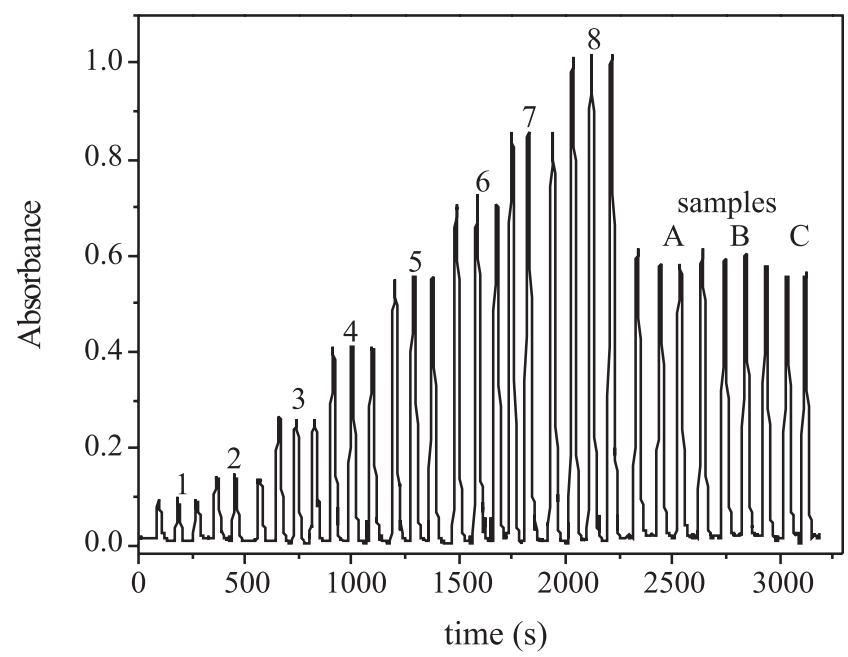

Figure 5S. Transient signals related to DXC determination. From the left $(A)$, recorded peaks refer to a eight analytical solutions $\left(5.37 \times 10^{-5}, 8.95 \times 10^{-5}, 1.79 \times 10^{-4}\right.$, $2.68 \times 10^{-4}, 3.58 \times 10^{-4}, 4.48 \times 10^{-4}, 5.37 \times 10^{-4}$ and $\left.6.27 \times 10^{-4}\right) \mathrm{mol} \mathrm{L}^{-1}$ plus three samples $(A, B$ and $C$ ) processed three times 